\title{
Management of ankyloglossia by diode LASER - A case report
}

\author{
Akhil $\mathbf{S}^{1 *}$, Jose Paul ${ }^{2}$, Johnson Prakash D'Lima ${ }^{3}$, Senny Thomas Parackal ${ }^{4}$, Deepak Thomas ${ }^{5}$, Archana NV \\ ${ }^{1,6}$ Postgraduate Student, ${ }^{2}$ Professor and Head, ${ }^{3,4}$ Professor, ${ }^{5}$ Reader, Dept. of Periodontology, Annoor Dental College and Hospital, Kerala, \\ India
}

*Corresponding Author: Akhil S

Email: akhilsurendran89@gmail.com

\begin{abstract}
Ankyloglossia or tongue-tie is caused by an abnormally short, thick lingual frenum restricting the normal movements and functions of tongue. The lingual frenum may be fibrous or muscular and the tie may be complete or partial. This article describes the surgical management of an 18 year old female patient with ankyloglossia associated with reduced tongue mobility and speech difficulty. The treatment included frenectomy using a diode LASER accompanied by tongue training exercise and speech therapy. The patient showed increased tongue movements with uneventful healing after six months.
\end{abstract}

Keywords: Ankyloglossia, lingual frenectomy, diode LASER.

\section{Introduction}

Tongue is a muscular organ with a variety of functions including breast feeding, chewing and articulation of speech. It is the only muscle in the body that has one end attached and the other end is free. Ankyloglossia (AG) or tongue tie is an oral congenital anomaly characterized by the decreased mobility of tongue tip. Wallace defined tongue-tie as "a condition in which the tip of the tongue cannot be protruded beyond the lower incisor teeth due to short lingual frenum." AG may cause problems that have occurred since birth, including breastfeeding and swallowing to lifelong

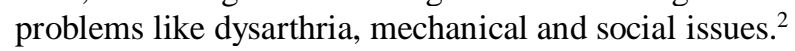

The prevalence of AG ranges from $0.1 \%-10.7 \%$. The prevalence in neonates $(1.72 \%-10.7 \%)$ is reported to be higher than in children, adolescents or adults $(0.1 \%-$ $2.08 \%) .^{2}$ Both genetic and environmental factors are involved in its etiology. An abnormally low tongue position can result in mandibular prognathism with maxillary hypodevelopment due to an excessive anterior thrust resulting in class III malocclusion. ${ }^{3}$ Higher tongue position may lead to tongue thrust causing anterior or posterior open bite. In addition excessive force during retrusion of tongue can cause blanching of tissues, gingival recession and midline diastema in lower central incisors. AG can be seen in some rare syndromes like Opitz syndrome, van der Woude syndrome, and X-linked cleft palate syndrome. Treatment of AG involves a surgical approach, including frenotomy and frenectomy, and a conservative approach, such as "wait-and-see" method.

\section{Kotlow's classification of ankyloglossia}

According to Kotlow's ${ }^{4}$ observation, AG can be of the following four types depending on clinically available free tongue (protrusion of tongue):

1. Class I: Mild ankyloglossia: $12-16 \mathrm{~mm}$

2. Class II: Moderate ankyloglossia: $8-11 \mathrm{~mm}$

3. Class III: Severe ankyloglossia: $3-7 \mathrm{~mm}$

4. Class IV: Complete ankyloglossia: $<3 \mathrm{~mm}$

\section{Case Report}

An 18 year old female patient reported to the department of Periodontics, Annoor Dental College and Hospital, Muvattupuzha, Kerala, India with a chief complaint of difficulty in speech and impaired tongue mobility. No relevant medical and family history reported. Short lingual frenum and limited tongue movements were observed on intraoral examination [Fig. 1,2]. She was not able to touch the roof of her mouth with the tip of the tongue when the mouth was open. She was diagnosed with class III anklyoglossia according to Kotlow's classification. There was no gingival recession in the lingual surface with respect to mandibular anteriors. LASER frenectomy of the lingual frenum was planned and the patient was informed about the treatment procedure and informed consent was obtained. Routine blood investigation report was analysed and was found to be within normal limits.

\section{Surgical procedure}

The lingual frenectomy was performed under local anesthesia with 2\% lignocaine and 1:80000 adrenaline. Frenectomy was initiated using a diode LASER (Photon plus Soft Tissue Diode LASER, 0.8W, 980nm) after complete anesthesia was achieved. LASER tip was applied in a brushing stroke from the apex of frenum to the base to cut the frenum [Fig. 3]. The ablated tissues were continuously wiped with a wet gauze piece.It takes care of the charred tissue and protects the underlying tissue from excessive thermal damage.

Protrusive movement of the tongue was evaluated to assess the complete removal of frenum [Fig. 4]. There was no bleeding postoperatively and no suturing was done. Moreover when conducting lingual frenectomy adjacent structures in the tongue and floor of the mouth must be taken into consideration. Care must be taken to avoid bilateral lingual arteries and nerves to preserve sensation of the tongue and to avoid bleeding. The genioglossus muscle runs from the symphysis of the mandible to the tongue and superficial to this genioglossus bilateral Wharton ducts are present through which submandibular gland drains. Care 
must be taken similarly to prevent difficulty with salivation or stricture of the duct.

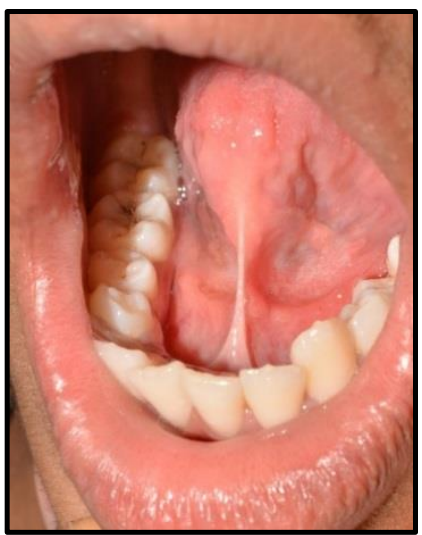

Fig. 1: Preoperative view showing thick lingual frenum

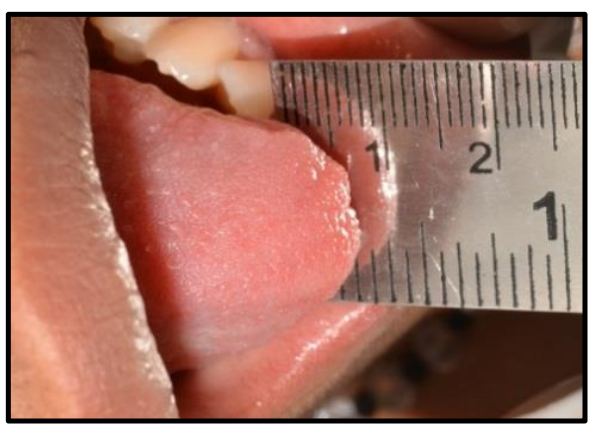

Fig. 2: Preoperative view showing limited tongue movements

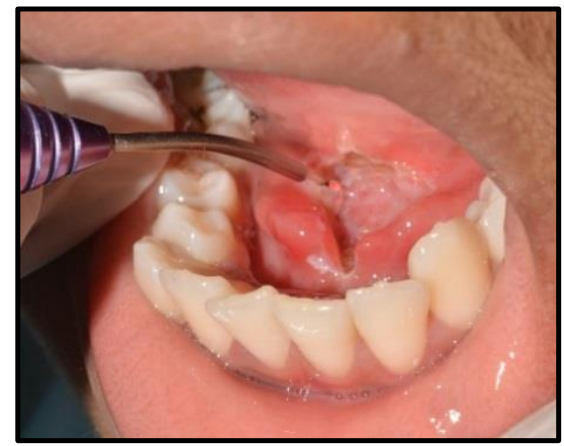

Fig. 3: Frenectomy using diode LASER

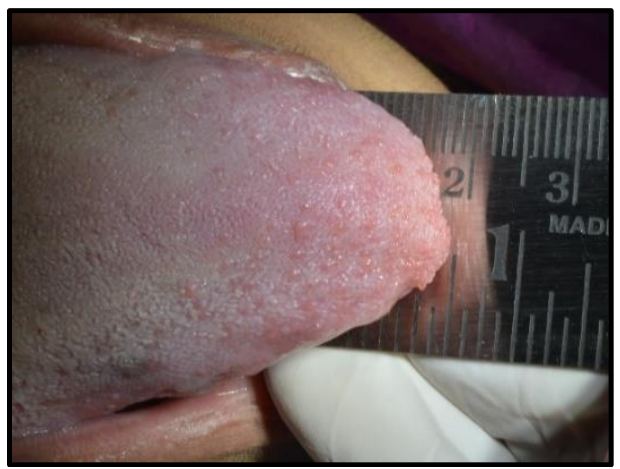

Fig. 4: Post surgical tongue movement

\section{Postoperative care}

The patient was prescribed Amoxicillin(500mg) thrice a day for 5 days and Nonsteroidal anti-inflammatory drug tablet Mefenamic acid (500mg) + Paracetamol (325mg) thrice a day for 5 days to prevent postoperative infection and pain and reviewd after 1 week.

Healing was uneventful [Fig. 5]. The patient was recommended the following tongue training exercises after 1 week. $^{5}$

1. Stretching of the tongue toward the nose and then downward.

2. Open the mouth widely, and try to touch the upper front teeth with mouth still wide open.

3. Licking of the upper lip from one side to other, and vice versa.

4. Repeat the same on your lower lip.

5. Close the mouth and poke both the cheeks as far as you can.

The patient was then referred to speech therapist for improvement of speech.After six months improved protusion of the tongue and speech was observed [Fig. 6-7].

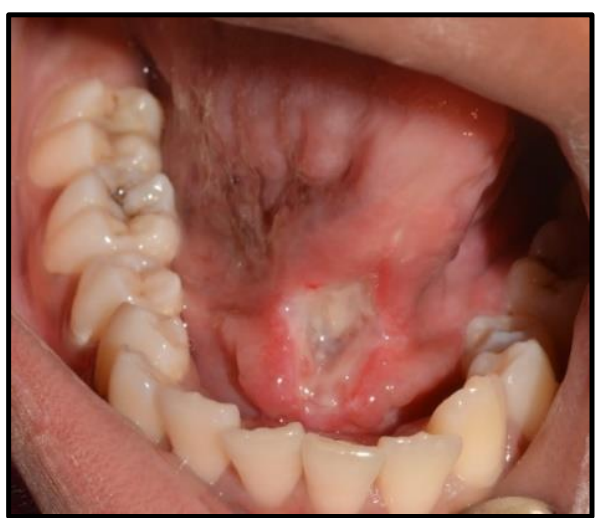

Fig. 5: One week postoperative view

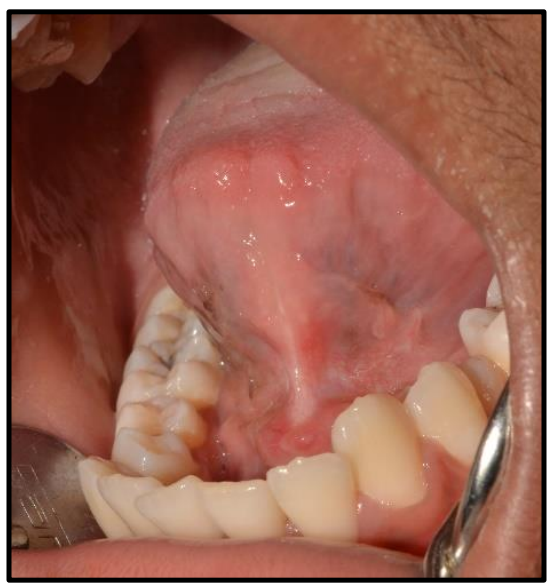

Fig. 6: Six months postoperative view 


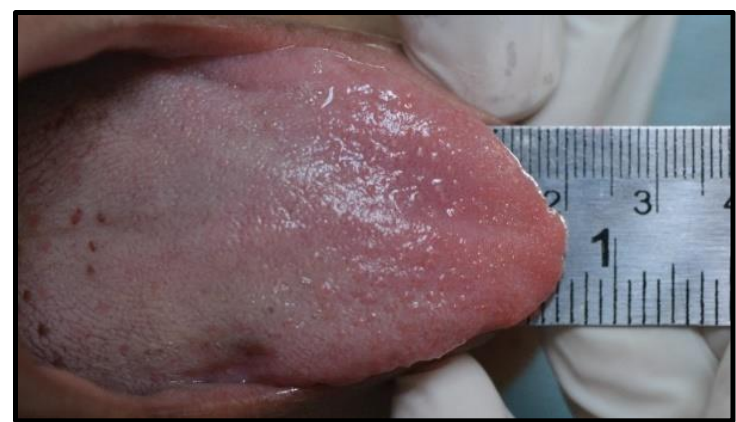

Fig. 7: Six months postoperative view showig increased protusive movement

\section{Discussion}

For pediatric patients, if there is feeding problems frenectomy is performed. Early surgery in a newborn with $<3$ months had maximum benefit in enhancing the mobility of tongue. ${ }^{6}$ There are many controversial beliefs about the casual relationship between AG and speech impairment. Many authors have criticized against the belief that speech is impaired by tongue-tie. Certainly children with AG are often found to have no speech problems. It is therefore advised that frenectomy should only be considered as a part of management of speech problem.

The difficulties in articulation are evident for consonants and sounds such as "s, z, t, d, n, l, j, zh, ch, th, dg." 7 However the most difficulty in producing lingual-alveolar sounds (particularly/l/) and interdental sounds (voiced and voiceless/th/) is that tip of tongue must be maximally elevated up to alveolar ridge to produce /l/ and maximally protruded up to lingual surface of maxillary incisors to produce /th/. Tongue-tie could be considered as a contributing factor if one cannot produce these sounds in the presence of all other speech sounds being produced normally. Therefore it is important to focus lingual-alveolar sounds when assessing the effect of AG on speech.

In this case the tongue-tie was found to be persistent since birth. However, the patient did not seek any treatment until she started social concerns regarding the condition. Several surgical techniques are available for managing lingual frenectomy like surgical frenectomy, electrocautery and LASER frenectomy.

Kotlow recommends the following structural guidelines to assess the need for the surgical management of lingual frenulum: ${ }^{4}$

1. If the tip of the tongue clefts during the act of protrusion.

2. If the tip of the tongue cannot sweep the upper and lower lips easily, without straining.

3. If retrusion of tongue blanches the tissue lingual to the anterior teeth.

4. If the tongue places excessive forces on the mandibular anterior teeth.

5. If the frenum interferes with normal deglutition process.

6. If lingual frenum creates diastema between mandibular central incisors.

7. If the child experiences speech difficulty due to limited tongue movements.
8. If infants, it shows abrasion at the underside of the tongue.

9. If the frenum prevents infant from attaching to the mother's nipple during nursing.

In LASER, most commonly used are Er: YAG, $\mathrm{CO}_{2}$ LASER and diode LASER. It can be used successfully in the management of lingual frenectomy. It can overcome the fear of blood, scalpel and local anesthesia. LASER surgery is less invasive, avoids bleeding and suture and eliminates the post-operative complications like swelling and inflammation. The LASER also has a significant antibacterial effect, which reduces the risk of inflammation.

The LASER-assisted surgery has several advantages as follows: ${ }^{8,9}$

1. Precise removal of tissue with better visibility, a clear dry field due to sealing off the blood vessels and lymphatic.

2. Reduces the risk of blood borne disease transmission due to its sterilizing effect while cutting.

3. Minimal pain and swelling have been reported after surgery.

4. Wound healing without scar formation and contraction.

5. Less damage to adjacent normal tissue.

Butchibabu et al. suggested that LASER-assisted frenectomies lead to increased patient acceptance due to reduced perception of pain during the procedure and postoperative periods. ${ }^{10}$ Decreased perception of pain can be attributed to protein coagulation at the wound surface that acts as a biological dressing, sealing the ends of sensory nerves. ${ }^{11,12}$ The postoperative periods were more comfortable for LASER as it causes less collateral damage, and also brings about sealing of lymphatics.

Patel et al. reported significantly less intraoperative bleeding with LASER-assisted frenectomy. It can be due to the coagulation of soft tissue proteins at high temperature of tissue ablation. ${ }^{13}$ Furthermore, the walls of blood vessels shrink at high temperature causing photothermal coagulation. ${ }^{14}$

\section{Conclusion}

Until late childhood, social concerns due to impaired tongue mobility may not become apparent. However functional limitation of tongue and social awkwardness due to the condition warrant surgical intervention in adolescent accompanied by speech therapy for optimum and positive outcome. Advances in LASER technology and a better knowledge of the bio-interactions of different LASER systems have extended its use in dentistry. They provide an excellent alternative to conventional scalpel surgery due to bloodless field, reduced pain perception and postoperative discomfort.

\section{Source of funding}

None. 


\section{Conflict of interest}

None.

\section{References}

1. Wallace A. Tongue tie. Lancet 1963;282:377-8.

2. Suter VG, Bornstein MM. Ankyloglossia: facts and myths in diagnosis and treatment. J Periodontol 2009;80(8):1204-19.

3. Messner AH, Lalakea ML. Ankyloglossia: controversies in management. Int J Pediatric Otorhinolaryngol 2000;54(23):123-31.

4. Kotlow LA. Ankyloglossia (tongue-tie): a diagnostic and treatment quandary. Quintessence Int 1999;30(4:259-62.

5. Singh M, Saini A, Singh PK, Tandon C, Verma S, Tewari T. Management of Ankylogossia by Frenectomy-A Case Report. J Adv Med Med Res 2016;18(8):1-5.

6. Ballard JL, Auer CE, Khoury JC. Ankyloglossia: assessment, incidence, and effect of frenuloplasty on the breastfeeding dyad. Pediatrics 2002;110(5):e63.

7. Ricke LA, Baker NJ, Madlon-Kay DJ, DeFor TA. Newborn tongue-tie: prevalence and effect on breast-feeding. J Am Boar Fam Pract 2005;18(1):1-7.

8. Rossmann JA, Cobb CM. Lasers in periodontal therapy. Periodontol 2000 1995;9(1):150-64

9. Rakhewar PS, Patil HP, Thorat M. Diode laser treatment of an oral squamous papilloma of soft palate. $J$ Dent Lasers 2015;9(2):114-7.

10. Butchibabu K, Koppolu P, Mishra A, Pandey R, Swapna LA, Uppada UK. Evaluation of patient perceptions after labial frenectomy procedure: A comparison of diode laser and scalpel techniques. Eur J Gen Dent 2014;3(2):129-33.
11. Fisher SE, Frame JW, Browne RM, Tranter RM. A comparative histological study of wound healing following $\mathrm{CO} 2$ laser and conventional surgical excision of canine buccal mucosa. Arch Oral Biol 1983;28(4):287-91.

12. Fenner J, Martin W, Moseley H, Wheatley DJ. Shear strength of tissue bonds as a function of bonding temperature: A proposed mechanism for laser-assisted tissue welding. Lasers in medical science. 1992;7(1-4):39-43.

13. Patel RM, Varma S, Suragimath G, Abbayya K, Zope SA, Kale V. Comparison of labial frenectomy procedure with conventional surgical technique and diode laser. J Dent Lasers 2015;9(2):94-9.

14. Levine R, Vitruk P. Enhanced hemostasis and improved healing in $\mathrm{CO} 2$ laser-assisted soft tissue oral surgeries. Implant Pract US 2015;8(3):34-7.

How to cite: Akhil S, Paul J, D'Lima JP, Parackal ST, Thomas D, Archana NV. Management of ankyloglossia by diode LASER - A case report. IP Int $J$ Periodontol Implantol 2020;5(1):41-4. 